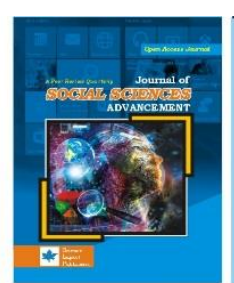

\title{
Journal of

\section{DEVELOPING A THEORETICAL MODEL TO EXAMINE FACTORS AFFECTING SCHOOL LEADERSHIP EFFECTIVENESS}

\author{
Phuc Quang Bao Tran¹, Linh Duy Nguyen², Khalida Parveen ${ }^{1}$ and Muhua Wang1 \\ ${ }^{1}$ Faculty of Education, Southwest University, Chongqing, China \\ 2Faculty of English Language, HUTECH University of Technology, Ho Chi Minh City, Vietnam
}

\begin{abstract}
What determines the success and effectiveness of leadership in schools? In the process of managing administrative and educational activities, the leadership effectiveness of school leaders is greatly influenced by a combined set of factors, possibly from leadership competencies and styles as well as local and global socio-economic landscape, latest advancements of science and technology, school culture, and change in modern leadership and management practices, etc. Based on extant literature review of rigorous studies on school leadership as the main methodology adoption, the present paper purposefully seeks to propose a theoretical model of school leadership effectiveness through investigating a network of relationships amongst leadership competencies, leadership styles, external and internal factors, and leadership effectiveness for global K-12 schools. Ultimately, the proposed model has both theoretical and managerial implications. Accordingly, an insight into the nature of these relationships will first expand the existing literature in school leadership and then activate school leader self-efficacy to enrich themselves with standout knowledge, skills, and qualities in the industry and simultaneously tailor their leadership styles to specific educational practices towards change and innovation to optimize leadership effectiveness.
\end{abstract}

Keywords: Leadership competencies; Leadership styles; External and internal factors; School leadership effectiveness

Corresponding Author: Phuc Quang Bao Tran, Email: baophucvt2008@gmail.com

(C) The Author(s) 2020.

\section{INTRODUCTION}

With the rise of globalization and current knowledge economy, human resources play a significant and strategic role of any society and all organizations as the human factor is inevitably a competitive advantage for success and sustainable development. Investment in the quality of human resources in both quantity and quality, most likely, yields results as expected and secures a better future for an organization. In most educational settings, school leaders are reasonably the biggest asset that defines success or failure, the image and reputation of schools to the community, and the driving force for creativity and innovation, etc., (Day \& Sammons, 2014; Schleicher, 2012). The pervasiveness of school leadership hallmarks, i.e. leadership effectiveness, competencies, and styles, has long captured the interest of educational community as key influencers for school success and improved student performance (The Wallace Foundation, 2009). Ultimately, a growing body of research has demonstrated the labyrinthine network of relationships among these leadership paradigms is closely correlated with the well-being of schools as well as the satisfaction and achievement of school personnel and students (Schleicher, 2012; The Wallace Foundation, 2009).

Globally, the issue of improving leadership competencies and styles for school leaders is recently addressed in efforts to develop qualified human resources in the process of educational reform and innovation (Gurr, 2015). In fact, over the past years, leadership effectiveness and its affecting determinants are actually not on the priority list of school leaders, resulting in the lack of relevant leadership knowledge and skills and the practices of inappropriate leadership styles, thereby eliminating work motivation of administrative staff and teachers (Hallinger \& Wang, 2015). Also, their gradually declined work productivity is conducive to weak and unhealthy relationships within schools (Hallinger \& Bryant, 2013). As a result, there is a shift of qualified personnel from the education sector to other professions as an alternative job for a career change. Students are consequently those that suffer the most from poor leadership practices.

Global research on leadership effectiveness, competencies, and styles as well as factors greatly affecting leadership practices is extremely diverse and rich in literature and methodology (Dufour \& Marzano, 2011; Felician, 2019; Hallinger, 2018). Conversely, these topics are not substantially addressed and theoretically synthesized to provide a comprehensive picture of school leadership effectiveness. Tackling this knowledge void will promise a fertile land for empirical and theoretical research. As for a desire to realistically examine the impact of leadership competencies and 
styles on leadership effectiveness, the main purpose is deliberately to develop a theoretical model of "School Leadership Effectiveness" based on relevant literature.

The remainder of the paper is structured as follows. The next section briefly reviews a general leadership-related theory and leadership in education. Then we proceed to present the conceptualization of leadership competencies and styles, external and internal factors, and leadership effectiveness, and their direct and indirect impacts on school leadership effectiveness from prior studies in more detail. The extensive review of literature pertaining to school leadership leads to the development of the theoretical framework. Finally, we offer the conclusion, theoretical and managerial implications, limitations, and directions for future research.

\section{Leadership}

It is of great difficulty to articulate what leadership truly means. Obviously, some definitions are well-established, and some probably 'dangerous'. The cohesive synthesis of leadership literature from Bush (2008), Daft (2008), Lunenburg and Ornstein (2012), and Northouse (2016), etc., has produced a relatively comprehensive leadership theorization. Accordingly, leadership is inherently a social process of influencing or shaping the actions and behaviors of others in an organized group towards the achievement of overall goals. Inevitably, those definitions encompass the frequency of common concepts such as 'influence', 'follower', 'process', 'situation', 'purpose', 'value', 'goal', 'vision', 'change', and 'organization', etc. All leadership theories automatically emphasize the concept of social influence and certain types of interaction between the three constituent elements of leadership practices, namely, leader, subordinates, and situation (Avolio et al., 2009; Bush, 2008; Northouse, 2016). Driven by the theoretical underpinning, leadership in this study is essentially crafted as the social influence or inspiration of an individual to maximize efforts of others, through his or her leadership competencies and styles, towards accomplishing a common goal and simultaneously the process of leadership practices is greatly affected by the external and internal factors in specific leadership environment and situations.

\section{Educational Leadership Theories}

Leadership theories and modes have evolved over time and are very rich in research topics and approaches (Avolio et al., 2009; Hallinger \& Wang, 2015). More specifically, recent research has drawn attention to Trait Theory of Leadership, Behavior Theory of Leadership, Contingency Theory of Leadership, and latest theories that distinguish between Transactional Leadership and Transformational Leadership, etc., (Khan et al., 2017; Lunenburg \& Ornstein, 2012; Northouse, 2016). Subsequently, the increased interest in the correlation between ethics and leadership in key decision-making leads to Moral Leadership (Friedman, 2001; Greenfield, 2004; Quick \& Normore, 2004; Solinger et al., 2019). Apparently, leadership theories and models continue to flourish according to the ever-changing needs of the socio-economic landscape. As for the development of a research model, this research is based on literature from the following theories:

\section{Trait Theory of Leadership}

Trait theory is a constant in leadership and management studies. Usually, research that resorts to this approach addresses the relationship between leadership effectiveness and certain traits and qualities of great leaders (Daft, 2008; Denhardt \& Campbell, 2005; Lunenburg \& Ornstein, 2012; Northouse, 2016), and wishes to answer the main question: "What are the key and pivotal personal qualities and characteristics that often contribute to effective leaders?". While the relationship between personal traits and leadership practices has not been conclusively tested in educational settings, more explicitly, this research highlights a set of compelling personality traits and qualities that effective school leaders potentially possess such as ambition to influence and inspire, commitment and passion to lead, great vision, self-confidence, emotional intelligence, high self-regulation, honesty and integrity, accountability, curiosity, creativity and innovation, resilience, etc., (Hoy \& Miskel, 2008; Mayger \& Provinzano, 2020; Northouse, 2016; Pont et al., 2008). While trait theory has its advantages to judge the likelihood of leadership effectiveness, the quest for a single list of universal qualities still eludes leadership and management scholars.

\section{Behavioral Theory of Leadership}

From the late 40s, researchers began to scientifically evaluate the behaviors and functions of great leaders in hopes of finding common patterns in their competencies and styles (Lunenburg \& Ornstein, 2012; Northouse, 2016). This approach centers around observable behaviors that potentially distinguish an effective leader from a non-leader and is based upon the hypothesis that ones can learn to become effective leaders through formal education and leadership experiences, rather than being inherent (Daft, 2008; Northouse, 2016). The behaviors of leaders are the best predictor of their leadership effectiveness in a given situation (Chen et al., 2017; Welch \& Hodge, 2017). Accordingly, there are two major issues in leadership behaviors: attention to work and concern for people in the organization, these are also the two best determinants for leadership effectiveness. Additionally, behavioral theory promotes the value of leadership competencies and styles with a focus on concern for people and collaborative decision-making (Daft, 2008; Lunenburg \& Ornstein, 2012; Welch \& Hodge, 2017). Defining goals, motivating employees to act and change, building reciprocal relationships, interacting effectively through various channels of communication, building team spirit, etc. are the top functional skills of effective leaders (Chen et al., 2017; Daft, 2008). 


\section{Situational Theory of Leadership}

The situational theory of leadership refers to the assumption that situational variables and competency and commitment level of members will determine the adoption of different leadership styles (Northouse, 2016; Thompson \& Glasø, 2015; Vroom \& Jago, 2007). Instead, leadership effectiveness will be more likely as long as leaders are apt to alter their leadership styles and strategies (The Center for Leadership Studies, 2017). Accordingly, the keys to this approach are adaptability and flexibility. The most effective leaders are those that are not static and adapt to diverse circumstances without relying on the same skills or traits (Vroom \& Jago, 2007). Instead, they will flexibly seek to transition from one leadership style to another to meet the changing needs of an organization and its employees. This approach demands a certain extent of leadership acumen to understand when change is inevitable and which leadership strategies are appropriate for each new paradigm. The subsequent move is to assess the situation and then apply the right leadership style. Also, an assessment of a given situation is more aligned with the consideration of leader-member relationship, nature of tasks, level of authority, and member maturity (Bush, 2008). Ultimately, a mono-style approach to leadership is not sufficient to work best and produce the initially intended results.

\section{Leadership Styles}

At first glance, leadership styles are on a continuum of development and no single style is the best at all times. A leadership style is often understood as a signature approach or method that leaders use to exert influence on subordinates. More specifically, a leadership style is a set of behavioral patterns that characterize the actions of leaders and are determined by their personal traits and qualities when directing, guiding, managing, and motivating people to accomplish the given objectives. Generally, there are many different leadership styles that can be portrayed and flexed by leaders as the situation calls. Psychologist Kurt Lewin's classic research suggests that the three major styles of leadership are Autocratic Leadership, Democratic Leadership, and Laissez-Faire Leadership (Billig, 2014). Subsequent research has identified more distinct and influential styles: Transactional Leadership and Transformational Leadership (Lunenburg \& Ornstein, 2012). The 3 leadership styles verified for this study are Transformational Leadership, Instructional Leadership, and Moral Leadership.

\section{Transformational Leadership}

Transformational leadership is often considered the most effective approach today to foster innovation. There is also a proliferation of empirical evidence that transformational leadership is positively associated with the effectiveness and efficiency within organizations. Leadership experts, e.g. James M. Burns and Bernard M. Bass, have continuously expanded the paradigm of transformational leadership as a process in which leaders encourage, inspire, and motivate followers to initiate innovation and create positive change (Bush, 2008; Day \& Sammons, 2014; Lunenburg \& Ornstein, 2012; Northouse, 2016). According to Northouse (2016), transformational leadership is a process that changes and transforms people. Generally, emotional values, moral standards, trust, strong sense of corporate culture, inspiration and motivation, creativity and innovation, and long-term goals, etc. are major concerns of transformational leaders and the focus on changing human values will in turn improve the organizational practices (Day \& Sammons, 2014; Northouse, 2016).

Bass (1985, as cited in Northouse, 2016) offers four components that constitute transformational leadership framework: Idealized Influence, Individualized Consideration, Inspirational Motivation, and Intellectual Stimulation. Specifically, transformational leaders make subordinates believe they are valuable contributors to the organization. The act of influence and inspiration inevitably aims to achieve results that exceed expectations by eliciting higher level of needs, building trust, making people feel recharged and energized, and helping every member grow as well, etc. Particularly, the approach is geared towards the encouragement to improve morale and motivation. This will then activate subordinate self-efficacy to gain more confidence that their change, creativity, and innovation are on the right track, leading to unexpected and remarkable results.

Leithwood (1994) conceptualizes eight dimensions of transformational leadership in education, namely (1) shared vision building, (2) goal setting, (3) intellectual stimulation, (4) individualized support, (5) models of best organizational practices and values, (6) high performance expectations, (7) productive school culture, and (8) incentives for decision-making participation. Also, transformational leaders generally exhibit a particular set of traits and characteristics such as inspiring, motivating, visionary, creative, charismatic, team-centric, understandable, engaging, emotionally intelligent, collaborative, etc. These frameworks of transformational leadership bring many advantages to school leaders, especially those with more autonomy, because they are traditionally described as mentors and role models as they lead by example and inspiration (Lunenburg \& Ornstein, 2012). Although it might not necessarily be the best approach for every situation, all of these traits make transformational leadership a right fit for schools where serious change is needed.

\section{Instructional Leadership}

Most school leaders are generally engaged in administrative practices that indirectly affect teaching and learning outcomes. Instructional leadership is well-suited to education when the emphasis of school leadership is on the quality of school instruction by influencing the interaction of teaching and learning and concentrating on continuous 
professional development (Day \& Sammons, 2014; Fidler, 1997; Hallinger \& Murphy, 1987; Hallinger \& Wang, 2015; Hoy \& Hoy, 2013; Reitzug et al., 2008). Effectiveness of instructional leadership in schools entails the balance between routine administrative practice and pedagogical work (Day \& Sammons, 2014; Hoy \& Hoy, 2013). More specifically, by immersing themselves in all aspects of the school system, school leaders' primary responsibilities range from defining and sustaining school vision, budgeting, using data to make decisions, empowering teachers and students, instructing and advising the academic team, managing curriculum development and evaluation, embracing the concept of learning community, to taking full accountability for the success of each member in their schools, etc., (Bush, 2008; Day \& Sammons, 2014; Hallinger \& Wang, 2015).

Also, to accomplish the goal of this coaching style, school leaders attach greater importance to the role of leadership supervision, quality of their instructions, and modeling and mentoring, etc., (Gurley et al., 2016; Hallinger \& Murphy, 1987; Hoy \& Miskel, 2008). Effective instructional leaders are first apt to clearly communicate school vision and goals to members (Hoy \& Hoy, 2013). Leadership is ultimately about monitoring the implementation of curriculum development, judging the quality of teaching and learning, checking and evaluating teacher and student progress, and making necessary adjustments, etc., through frequent observations and constructive dialogues (Gurley et al., 2016; Hallinger \& Murphy, 1987; Hoy \& Sweetland, 2007). Additionally, the delivery of high-quality instruction is often accompanied by clarity, support, and necessary resources to enable them to work more effectively. To maximize leadership effectiveness, there is always a tendency to empower school members for shared leadership and accountability (Pont et al., 2008). Finally, all school staff are encouraged to continue learning and proactively participate in social and academic activities, which is conducive to a learning community.

\section{Moral Leadership}

The truth is morality matters for schools. As the growing number of moral incidents in schools recently goes viral, moral leadership is always a requirement. Literally, moral leadership in its purest sense refers to the process of providing moral values and beliefs for people to grow, inspiring them to act, helping them define the problems they face, and effecting change in leading self and then others, etc. to accomplish a higher order of moral purpose (Kalshoven et al., 2011; Solinger et al., 2019). Moral leadership lays greater emphasis on the role of ethics in key leadership decisions as effective leaders believe the practice of ethical behaviors leads to better results (Brown et al., 2005; Quick \& Normore, 2004; Solinger et al., 2019). Also, it encompasses the implication of serving others as moral leaders put the needs and interests of others first (Daft, 2008; Solinger et al., 2019).

As ethical leaders are people-oriented, school leaders always take the lead by acting as moral role models for school members to follow and usually suppressing amoral acts (Langlois et al., 2014). As school leaders are in the full authority and entrusted power over schools' matters, they are likely to engage in degraded morality and educational corruption due to lack of good moral values. Apparently, the effects of moral degradation and educational corruption are very devastating for schools and society. The practice of moral leadership is inevitably critical to school leaders to minimize demoralization and corruption through inculcating moral values. The introduction of this model to school leaders, therefore, aims to inform and awake them to uphold good moral values of integrity, honesty, authenticity, accountability, transparency, fairness, etc., which will ultimately result in increased leadership effectiveness (Brown \& Trevino, 2006; Kalshoven et al., 2011).

After all, there is no perfect leadership style for school leaders. Generally, effective leaders are those that can skillfully and flexibly combine styles at the right time in specific environment and situations by relying on available resources. School leaders with appropriate leadership styles will likely drive the schools to success. Conversely, if school leaders with inappropriate leadership practices will inhibit the development of schools. Schools then will lack cohesion, mutual respect, and cooperation and support for each other, leading to deteriorating performances.

\section{School Leadership Effectiveness}

Leadership is a process while leadership effectiveness is an outcome. As the primary driver for growth and innovation, leadership effectiveness refers to the degree to which leaders brings success, transformation, and innovation to an organization (Kotze \& Venter, 2011; Lee et al, 2019; The Wallace Foundation, 2009). In this sense, effective leaders likely succeed in influencing and motivating members to work together to accomplish the desired goals, creating profits, and maintaining a good reputation for the organization (Day \& Sammons, 2014; Dufour \& Marzano, 2011; Hargreaves, 1995; Mulford, 2003). Generally, key criterion for measuring leadership effectiveness metrics can vary widely in terms of performance outcomes, achievement of goals, survival and growth, ability to deal with crises, members' satisfaction with leaders and organizations, psychological development and maturity of members, leaders' image in the mind of their subordinates, reputation of the organization, success in change and innovation, etc., (Hoy \& Miskel, 2008; Lunenburg \& Ornstein, 2012; Mitchell et al., 2015; Mulford, 2003).

School leadership effectiveness manifests that schools are likely achieve the expected results and educational efficiency within the limited resources and meet the requirements of individual and socio-economic development of the community and the quality human resource needs of the society (Day \& Sammons, 2014; Schleicher, 2015). More specifically, schools with leadership effectiveness have clear and specific missions and visions, from which every 
school member shares knowledge, skills, and data and is intrinsically committed to responsible implementation of educational goals (Day \& Sammons, 2014; Parveen et. al., 2021; Schratz \& Schley, 2014). Also, school leaders and teachers are competent to flexibly apply professional knowledge and adjust different leadership styles depending on specific situations and student needs (Dufour \& Marzano, 2011; Lunenburg \& Ornstein, 2012). Additionally, leadership effectiveness embraces the idea of creating a supportive, professional environment in which all members are unleashed their natural creativity to effectively foster innovation (Lee et al., 2019; Schleicher, 2015; Tomlinson, 2004).

Principals are not the only leaders but "a leader of all school leaders" and teachers and students are always empowered in administrative and instructional decision-making process (Pont et al., 2008). Families, community, and social forces are also encouraged to participate in school educational activities. Another manifestation of leadership effectiveness is not only the fixed regulations of the administrative management but also the development of personality and quality of school leaders, administrative staff, teachers, and students (Dufour \& Marzano, 2011). Accordingly, effective leadership implies the transformation from a passive leader/member to a dynamic and innovative one in the face of change and challenges, quickly adapting to all situation variables to grow and flourish according to the increasing demands of society. Therefore, leadership effectiveness is likely to result in the success, development, growth, and sustainability of schools (Dufour \& Marzano, 2011; The Wallace Foundation, 2009; Tomlinson, 2004).

Most educational scholars and school administrators are much interested in the quality of education but pay little attention to the effectiveness of school leadership. It is due to the fact assessing leadership effectiveness depends on many influential factors and collaboration of many resources in society. This research purposefully investigates school leaders' level of leadership effectiveness in correlation with leadership competencies and styles, which are basically derived from their knowledge, qualities, skills, and experiences.

\section{Leadership Competencies}

Leadership competencies in this theoretical research represent a combined set of distinctive knowledge, skills and experiences, and personal traits and attitudes school leaders exhibit in the practices of self-leadership and school leadership to generate competitive advantage and contribute to superior performance (Adair, 2010; Day et al., 2011; Hollenbeck et al., 2006; Karia et al., 2019). Not everyone is born to be an effective leader and there are knowledge, skills, and qualities that are likely to be learned and cultivated through the practical experiences. To optimize leadership effectiveness, school leaders are expected to capture their need for additionally requisite competencies in the industry (Seemiller \& Croft, 2017; Tomlinson, 2004). This inevitably helps school leaders position where they are in the journey of leadership and management, so that they are apt to continuously develop themselves to become more effective leaders.

\section{Leadership and Management Knowledge}

Knowledge is a source of power to lead. The general knowledge, e.g. politics - law, culture and society, science and technology, emotional intelligence, foreign languages, etc., really creates the foundation for school leaders to grow on personal and professional level (Kotze \& Venter, 2011; Stevenson et al., 2016). Professional knowledge refers to the understanding of fundamental principles of educational science and educational leadership and management paradigms that school leaders perceive, and accumulate through continuous education and actual experiences, and are able to apply the knowledge in their leadership practices (Bush, 2008). More specifically, a good grasp of leadership and management theories and models (e.g. school development strategies, human resources management and development, organizational culture, change management and school innovation, and international economic integration, etc.) make school leaders feel competent to foster change and innovation (Schleicher, 2015; Seemiller \& Croft, 2017). Besides, considerable expertise in curriculum development and management, testing and evaluation, educational research, etc., actually contributes to instructional leadership within schools. Not surprisingly, the knowledge is a must for making decisions to optimize leadership effectiveness.

\section{Leadership Skills}

Leadership skills are valuable assets to show the ability and proficiency of school leaders to turn above-mentioned knowledge into actions and effectively deliver extraordinary performances towards the achievement of set goals (Adair, 2010; Pont et al., 2008). Effective school leaders generally rely on a number of essential skills related to selfleadership, team leadership, and organizational leadership. Self-leadership advocates mastering some requisite skills (e.g. self-understanding, cognitive flexibility, work and life balance, critical thinking, and problem-solving, etc.) to intentionally transform oneself through self-influence to become more effective from the inside out (Adair, 2010; Kotze \& Venter, 2011; Norris, 2008; Tomlinson, 2004). The comprehensive concept of team leadership naturally exhibits certain skills that activate school leaders to genuinely and positively interact with their team members, such as skills related to all forms of communication, motivational encouragement, data-driven decision-making, task delegation, team development, influence and image building, relationship building, conflict management, and member empowerment, modeling and mentoring, etc., (Adair, 2010; Karia et al., 2019; Kotze \& Venter, 2011). To reach a higher level of leadership, organizational leadership skills highly sought after by effective leaders are closely 
correlated with vision building and strategic thinking, policy-making, organizational management, work organization and implementation, allocating and mobilizing resources, building a positive school culture, change management and innovation, community relations, etc., (Adair, 2010; Karia et al., 2019). A combined set of these standout skills is the most important pillar for school leadership effectiveness regardless of situation variables school leaders are likely to face (Northouse, 2016; Solomon \& Steyn, 2017). Luckily, leadership skills can be learned, and the continuous development of these skills truly benefits leaders and schools.

\section{Leadership Qualities and Attitudes}

Leadership qualities and attitudes of school leaders greatly pay a key role in determining the effectiveness of their leadership competencies and styles (Adair, 2010; Karia et al., 2019; Kotze \& Venter, 2011; Schleicher, 2015). Certain qualities that stand out as fundamentally important include futuristic vision, commitment and passion, honesty and integrity, positive emotions, constant innovation and creativity, flexibility and responsiveness, accountability, professional ethics, transparency, generality, confidence, etc., (Gurr, 2015; Judge et al., 2002; Karia et al., 2019; Pont et al., 2008). Also, for effective school leaders, a high level of emotional intelligence will invariably carry significant weight on their journey to the top. Leadership begins when school leaders have the right attitude which in turn correlates strongly with overall leadership effectiveness (Karia et al., 2019; Kotze \& Venter, 2011). For example, school leaders' choice of positive attitudes will definitely set the tone of their influence over other members (Karia et al., 2019). Additionally, proper attitudes towards change and innovation make major difference between success and failure. Fortunately, these standout leadership qualities and attitudes can be naturally acquired and developed through actual experiences and personal training.

\section{External Factors}

\section{Legal-Political Environment, Economic Context, and Socio-Cultural Values}

There is no form of educational organization, whether public or autonomous, is immune to politics. The legal-political environment refers to the current political institution and stability, degree of centralization or decentralization, and a system of legal documents, policies, laws, guidelines, and regulations, etc., (Wales et al., 2016). The policies and guidelines of the ruling government exert a macro impact on the educational environment and development strategies of schools (Hallinger, 2018; Miller, 2018; Pashiardis et al., 2018; Pont et al., 2008). A stable political and legal environment will inevitably facilitate school leadership and management. Additionally, decisions about school leadership or administration are strictly framed under the provisions of applicable laws and regulations (Wales et al., 2016). Simultaneously, legal documents clearly define the roles, responsibilities, obligations, and rights of each members in schools. The purpose of the legal system is inherently to maintain a fair, safe, and equal educational environment, and to protect the rights, obligations, and legitimate interests of school members. Governance and its relationship with leadership are the most challengeable area for school leaders right in the way to accomplish their duties (Parveen et. al., 2021).

When an economy changes, it will greatly affect the well-being of education system and the general operation of schools (Miller, 2018). Economic growth or decline entails inevitable change in management and leadership of school leaders (Pashiardis et al., 2018), e.g. redefining sustainable development strategies, adjusting financial policies and allocating resources, adding/cutting more pieces of facilities, ensuring minimum working conditions, etc. Countries with developed socio-economic conditions, for instance, will likely prioritize more resources for education (Retna, 2015). The investment of resources in schools also requires creativity and innovation in management and leadership practices to improve the efficiency and quality of school performance (Welch \& Hodge, 2017).

Socio-cultural values and factors such as a set of beliefs, traditions, habits, lifestyle, human rights, ethnicity, attitudes towards quality of life, gender role in society, etc., are inherently the foundation and basis for the formation and selection of values, ethics, standards, relationships, behaviors, styles, etc., in schools (Bush \& Glover, 2003; Miller, 2018; Northouse, 2016; Tomlinson, 2004). The socio-cultural background simultaneously exerts a considerable influence on the identity of school leaders and shape how they engage and approach leadership and management practices (Dimmock \& Walker, 2002; Miller, 2018; Seemiller \& Croft, 2017). Generally, finest traditional values that advocate the standards for school leaders are patriotism, solidarity, national pride, respect for people, sense of community, courage, professionalism, etc.

Recent trend of socio-economic globalization has brought many opportunities to promote cultural exchanges, adopt advanced educational technology, access to rich educational resources and international cooperation, and develop human resources, etc., (Bush, 2008; Turan \& Bektas, 2013). However, the challenge facing school leaders today is how to change and innovate effectively to make breakthrough steps in school leadership. Effective school leaders, therefore, cannot ignore any sensitive move of the socio-economic and political factors.

\section{Advancement of Information Technology}

There is no denying the role of information technology in improving the quality of school instructions (Afshari et al., 2009). Especially, the latest advancements of artificial intelligence, automation, and educational technology, etc., have brought an extremely diverse and rich knowledge flatform, and useful tools for school leaders, making access to 
professional knowledge and academic community much simpler and simultaneously maximizing the effectiveness of school leadership (Tam et al., 2017; Uğur \& Koç, 2019). Inevitably, education during the COVID-19 pandemic has changed dramatically with the distinctive rise of e-learning thanks to the advancement of information technology.

But whether cutting-edge educational technology resources, e.g. educational management software, cloud computing, STEM materials or robotics, etc., can come to schools depends on the innovative thinking and courage of school leaders (Sincar, 2013). The advancement of science and technology entails high investment and training costs, and schools may be faced with solving problems regarding the effectiveness and quality of training programs (Sincar, 2013; Uğur \& Koç, 2019). The explosion of educational technology will then create non-traditional modes of educational leadership and gradually change perspectives and approaches to school management and leadership.

With the development of technology 4.0, an extensive intelligent ecosystem is likely to contribute to educational change in the new era. Effective school leaders are, thus, expected to be pioneers in digital transformation, paying adequate attention to continuously making use of latest educational techniques and technologies. It is socially required that school leaders regularly hone and foster technological skills, especially those related to technology 4.0 application, to maximize the effectiveness of leadership and management and then improve the quality of education (Uğur \& Koç, 2019).

\section{Human Resources Competition}

Competition in the 4.0 era is the competition for high-quality human resources. When the economy is mainly based on knowledge, plus the trend of international integration and globalization, highly qualified human resources play a decisive role in national competitiveness. Human resources are inevitably the biggest asset of schools. Qualified personnel make up the core of management and leadership practices as schools today are influenced by a competitive and constantly changing educational environment (Bush, 2008; Stevenson et al., 2016). In fact, schools' finance, facilities, and science and technology, etc., are all limited, they can only generate efficiency when combined effectively with human resources.

Highly valued and experienced faculty will make a great decision on the effectiveness of schools' instruction, management, and leadership (Mitchell et al., 2015). Skilled and talented personnel are the decisive factor to restructure the school organization, transform the model of management and leadership, promote innovation and creativity, apply latest advancements of science and technology, and increase schools' competitive advantage, etc., (Day \& Sammons, 2014; Schleicher, 2015; Pont et al., 2008). Access to talents closely correlates with a reasonable human resource development policy, improved work environment, and appropriate remuneration policies to attract new staff and maximize retention. In general, school leaders can attribute leadership effectiveness to the concept of competing for high quality human resources.

\section{Change and Change Management}

All things and phenomena in life are constantly moving and changing. Change in the socio-economic, sciencetechnology context has led to change in the education system and schools. Change in schools can be due to the sociocultural requirements for schools, maybe because schools themselves find it difficult to survive and develop without change (Ibrahim \& Don, 2014). Ultimately, change management in schools is a current trend, challenge, and innovative solution (Ibrahim \& Don, 2014; Schratz \& Schley, 2014).

In school management, responses to change are usually viewed as an opportunity to escape from old habits that hold back school leaders and hinder their leadership growth, creativity, and innovation (Adair, 2010; Ibrahim \& Don, 2014; Lunenburg \& Ornstein, 2012; Tomlinson, 2004). Change management helps school leaders to recognize their own strengths and weaknesses as well as to judge the correlation between their leadership competencies and leadership effectiveness and what is not appropriate in their leadership styles. For example, preparing plans or scenarios to avoid being passive in a context similar to the Covid 19 epidemic is an evidence that school leaders show how they are capable of using all available resources to cope with the situation to keep schools going while waiting for specific instructions from all levels of state management. When change is successful, they have effectively generated influence and inspiration within schools, strengthening a position in schools, building an influential image to school members, and enabling a reputation in the community, etc. Conversely, if change fails, valuable lessons for school leaders are new experiences, knowledge, and skills to lead and manage better.

\section{Internal Factors}

\section{School Finance and Salary Policies}

Finance is inevitably a must in running the day-to-day operations of schools. School budgets refer to policies of mobilizing funds and managing expenses for educational activities to provide educational opportunities and achieve the goal of improving the quality of instruction. Sources of revenues that support school budgets come from the state or local funds, contributions from families-community-businesses, domestic and international donors, etc. Right from school leaders' wish to develop a new program, recruit new staff, add more pieces of equipment, send teachers to professional development courses, or organize events, etc., money determines everything. Undoubtedly, finance is critical to decision making in leadership and management practices (Davis et al., 2005). With greater funds, decisions 
in managing and monitoring planned activities are made faster. However, sometimes it is not a matter of more or less, but how school leaders use money effectively. Conversely, mistakes in finance management likely lead to internal disunity and adversely affect leadership effectiveness.

Salaries are the main income of all school members and critical to their satisfaction and motivation in the most basic sense. Reasonable salary policies are the driving force to promote the strength of human factor in the implementation of educational goals. Schools with the practices of reasonably competitive compensation policy will easily attract highly valued personnel, retain talents, and motivate members to work effectively (Pont et al., 2008). It is essential to first structure base salary so school leaders can live on monthly salaries and have a feeling of being secure and stable in their work. Additionally, timely bonuses and incentives are the most likely drivers of retaining effective leaders and simultaneously boosting their loyal, resulting in increased labor productivity (Pont et al., 2008).

\section{School Culture}

School culture is always a central concept in the science of school management and leadership. School culture generally refers to as a set of well-established standards, shared values and beliefs, rituals and traditions, artifacts and symbols, school climate, and physical landscape, etc., that shapes the appearance and atmosphere of schools and greatly influences members' perspectives (Lunenburg \& Ornstein, 2012; Miller, 2018; Turan \& Bektas, 2013). Additionally, there are traditional festivals or events to celebrate throughout the academic year. These tangible and spiritual values give schools their own characteristics and uniqueness that distinguish one school from another (Feliciano, 2019; Miller, 2018). Basically, manifestations of a positive school culture include the respect of educational values, desire for continuous professional development and lifelong learning, appreciation of creativity and innovation, teacher and student empowerment, nurture of a democratic atmosphere, etc., (Miller, 2018; Waldron \& McLeskey, 2010).

Most school leaders have an instinctive awareness that school culture is crucial to school success (Engels et al., 2008; Hargreaves, 1995). When the core values of school culture are geared towards communication, collaboration, relationships, productivity, creativity, and innovation, etc., school leaders will feel a sense of significance and have a greater incentive to strive for their maximum potential (Engels et al., 2008). A positive school culture is conducive to their professional satisfaction and leadership effectiveness as it provides a safe, supportive environment for school leaders' performance to evolve (Lunenburg \& Ornstein, 2012; Tomlinson, 2004). Satisfied school leaders are more apt to tailor their approaches to school leadership, and better prepared to lead their schools towards success.

Schools with a strong culture will always set high expectations of their members. The term also encompasses the beliefs and expectations of school leaders that are reflected in their leadership and management practices. These expectations are ultimately aimed at improving the effectiveness of leadership and management, quality of school instructions, and student performance. In a strong school culture, constant communication and collaboration blossom (Turan \& Bektas, 2013). It is like glue that binds school members together into a block, likely encouraging positive comments and limiting negative expressions and risks of misunderstanding and potential conflicts. Ultimately, in a healthy environment, positive behaviors and attitudes exhibited by school leaders will become contagious, soon widely spreading to other school members and in turn improving the wellbeing of all.

\section{School Autonomy and Countability}

School autonomy is inevitably a powerful management practice that comes with opportunities and challenges for school leaders. School autonomy refers to gaining greater authority to proactively make decisions in a more responsive, creative manner based on school needs and specific contexts (Christ \& Dobbins, 2016; Keddie et al., 2017). The issue of autonomy is primarily related to 4 major areas: finance, human resources, organization, and pedagogical direction. An insight into the nature and content of autonomy mechanism is critical for school leaders. The truth is that greater autonomy entails overwhelming responsibilities for school leaders (Keddie \& Holloway, 2019).

Autonomy is indispensable for school leaders to be dynamic, creative, and innovative in school management and pedagogical decisions (Keddie, 2014; Keddie et al., 2017; Schleicher, 2015). To some extent, what school leaders aspire is the necessary independence from external interventions and greater control over internal management such as the allocation of financial resources, staff recruitment, curriculum development, and teaching and learning standards, etc. More apparently, greater control requires being more proactive in decision-making process in all school aspects, but suitable to the school conditions, resources, and circumstances. Importantly, autonomy is an opportunity for school creativity and innovation (Baum \& Baumann, 2019).

School autonomy, however, is like a double-edged sword that school leaders probably run the risk of abusing their power and overreaching the limits of their authorized functions and responsibilities (Keddie et al., 2017). Along with the delegation and exercise of autonomy questions the issue of growing accountability and alignment with government regulations (Keddie \& Holloway, 2019). Accordingly, there are the responsibilities of ensuring quality as committed, using effectively and transparently sources of funds, developing schools in a sustainable way, and maintaining and enhancing schools' reputation for the benefits of school members as well as community. When implemented effectively, school autonomy ensures the best outcomes for leadership. 


\section{Teacher Leadership and Autonomy}

Advocates for school reform and innovation claim that teacher leadership and autonomy will have a greater influence on many school matters outside the classroom (Avidov-Ungar et al., 2014; Fairman \& Mackenzie, 2014; Schleicher, 2015). Given schools' current increased workload, it seems apparent that school leaders do not have enough time and personal resources to effectively manage it all. In order to optimize leadership effectiveness, empowering teachers is a clever strategy for shared decision making and accountability. Teacher leadership and autonomy will likely produce long-term benefits to both school leaders and teachers if done properly (Schleicher, 2012; Skaalvik \& Skaalvik, 2014). Obviously, when teacher empowerment works, school leaders do a good job of influencing and inspiring their subordinates.

Specifically, teacher leadership and autonomy help reduce school leaders' work pressure, while giving teachers opportunities to do new tasks. School leaders then have more time and efforts focusing on important and long-term plans and strategies. When empowered with leadership role, teachers will be potential partners in school leadership and management, especially pedagogical activities (Avidov-Ungar et al., 2014). Accordingly, teachers are given greater autonomy over the content and methods of instruction and proactive in testing and evaluation of their students. Ultimately, tailoring their instruction towards student-centered emphasis is positively correlated with student outcomes (Fairman \& Mackenzie, 2014).

Teacher empowerment and autonomy positively affect teachers' attitudes, behaviors, beliefs, and creativity and innovation, which then improves the work environment and enhances school culture (Avidov-Ungar et al., 2014; Inandi \& Giliç, 2016; Schleicher, 2015). Obviously, teachers will feel valued to schools and see themselves respected by their inspiring leaders. Teachers will proactively develop themselves for latest knowledge and skills, make full use of their initiative and creativity, and actively collaborate with their colleagues, in the long run, they will build the strength of teachers' collective and this is definitely beneficial for school leaders (Fairman \& Mackenzie, 2014). Opportunities given to teachers gradually enrich their professional knowledge and skills accompanied by increased motivation, satisfaction, commitment to schools, and accountability to the society (Day \& Sammons, 2014; Wadesango, 2012). Ultimately, schools are the collective of effective educational leaders.

\section{Continuous Professional Development}

Science of educational leadership and management is constantly evolving. Today's leadership competencies and styles may no longer be relevant and effective tomorrow due to higher demands and fierce competition in the industry. School leaders nowadays are socially expected to be influential spiritual leaders, strategic visionaries, curriculum developers, instructional leaders, assessment experts, community builders, communication and public relations experts, financial analysts, facilities managers, special program administrators, etc. (DeVita, 2005). Obviously, high standards of professionalism for modern school leaders are frequently perceived as being more credible and reliable (Pont et al., 2008; Tam et al., 2017).

Continuous professional development gives school leaders the opportunity to break out of their old habits of leadership and management that hinder their growth and well-being. This simultaneously motivates school leaders because they feel like they are getting the professional help they need to be more mature and effective in school leadership (Mulford, 2003; Retna, 2015; Schleicher, 2012).Professional development improves the competencies of inexperienced leaders through collaborative work and direct instruction from other experienced leaders to become more effective educators of the future (Mitchell, 2013).Through professional development programs, careerconscious school leaders can constantly hone their skills to be more proficient in their work as effective leaders aspire for professionalism in school administration (Mitchell, 2013; Tomlinson, 2004; Zachariou et al., 2013). To optimize the use of human resources, it is especially important for school leaders to encourage all members to pursue their continuous professional development (Stevenson et al., 2016). As a result, highly qualified staff maximize leadership effectiveness.

\section{School-Family-Community Partnerships}

Education is inevitably a highly social activity. Only the education system and schools cannot do well in educating students. In order to achieve the goal of comprehensive education for students, it is necessary to attach greater importance to school-family-community partnerships (Bush \& Glover, 2003; Frederico \& Whiteside, 2015; Hallinger, 2018; Hampden-Thompson \& Galindo, 2016; Valli et al., 2016). Apparently, mobilizing external forces and expanding win-win relationships benefit school leaders in involving stakeholders to participate, invest, and finance schools' education and training process (Frederico \& Whiteside, 2015). The quality of student care and education depends much on the level of participation of families and community (Molina, 2013). Effective school leaders learn family and community engagement and shared responsibility promote cohesion and create optimal conditions for sustainable development (Hallinger, 2018). Strengthening school-family-community relationships is also a strategic policy in socializing education.

To be specific, strengthening this partnership and exploiting its value can help school leaders solve financial difficulties, access scientific and technological achievements, and maintain a competitive edge in today's dynamic 
market (Frederico \& Whiteside, 2015; Molina, 2013). Parents and community may not always support school decisions, but the school-family-community relationship when built on trust helps them understand what schools are doing and they are willing to share responsibility with schools. Direct dialogues or the presence of successful community figures in decision-making process benefit school leaders a lot, especially in terms of long-term development strategy and vision or leadership and management experience from successful businesses, etc., (Frederico \& Whiteside, 2015; Valli et al., 2016). This partnership also provides professional development opportunities for school members through conferences and forums and then fosters creativity and innovation. Regarding mobilization of community resources for school development, this is the hardest job of school leaders. Ultimately, if done successfully, it produces many positive effects to school leadership (Hampden-Thompson \& Galindo, 2016).

\section{Theoretical Framework for School Leadership Effectiveness}

Based on the leadership literature as mentioned above, the portrayal of school leadership effectiveness is conceptualized as a multidimensional model displaying the relationships amongst leadership competencies, leadership styles, and leadership effectiveness as the main dimensions. Additionally, the inevitable impact of external and internal factors on the dimensions and the overall school leadership practices is simultaneously displayed for a comprehensive landscape of school leadership effectiveness (Figure 1).

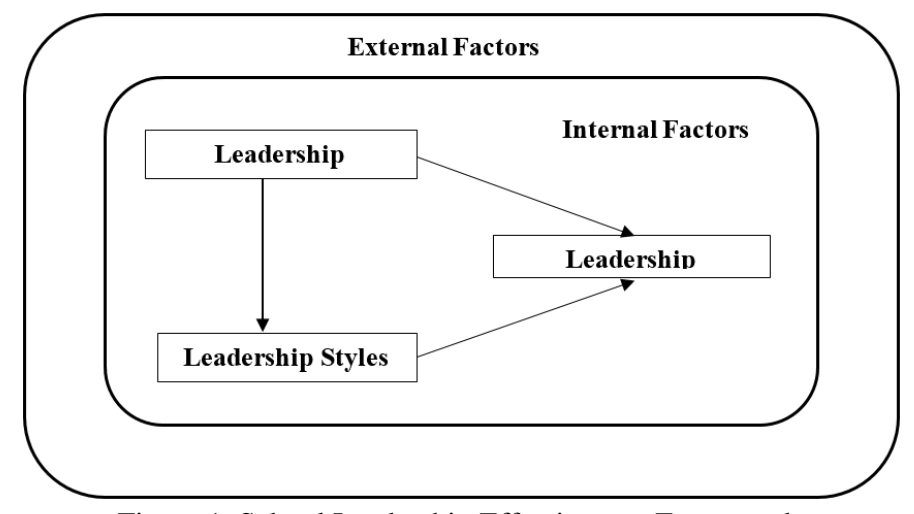

Figure 1. School Leadership Effectiveness Framework.

More specifically, leadership competencies are directly measured by a set of 3 concepts: (1) Leadership Knowledge, (2) Leadership Skills, and (3) Leadership Qualities and Attitudes. Additionally, leadership styles verified for this model include: (1) Transformational Leadership, (2) Instructional Leadership, and (3) Moral Leadership. Similarly, external factors affecting the process of school leadership practices are: (1) Socio-Cultural and Economic Elements, (2) Advancement of Technology and Science, (3) Human Resources Competition, and (4) Change and Change Management. Internal factors influencing leadership competencies and leadership styles are: (1) School Culture, (2) Continuous Professional Development Policy, (3) School Autonomy, (4) Teacher Leadership, and (5) School-FamilyCommunity Partnerships (Figure 2).

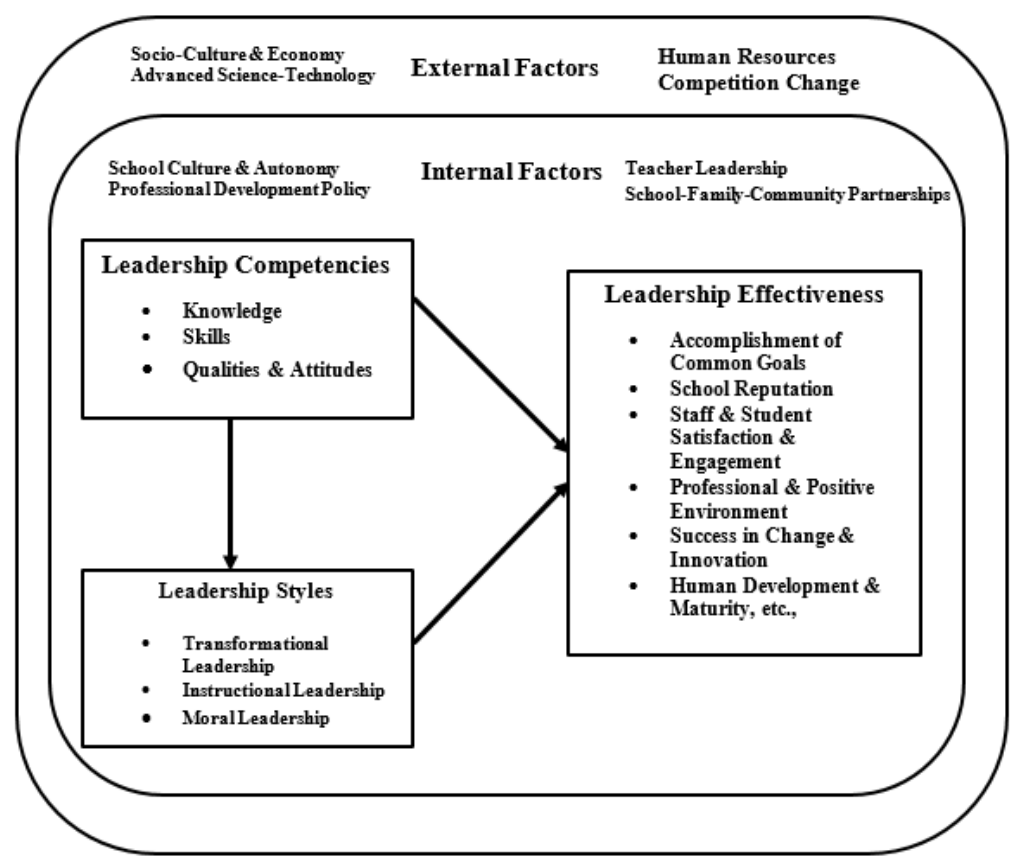

Figure 2. Detailed Dimensions of School Leadership Effectiveness Framework. 


\section{CONCLUSION}

The volatile, risky, and complex context of the Industrial Revolution 4.0 has broken the structure of most organizations both in breadth and depth. Leading schools in the knowledge economy and the 'digital world' era is completely different and more challenging than ever before. Schools today call for more strong, effective, and visionary leaders to face current and future educational challenges and opportunities. Accordingly, effective school leaders transform challenges into opportunities to create change and launch innovation in their management and leadership practices for personal and school growth. Ultimately, it is of great importance for career-conscious school leaders to redefine concepts of leadership and leadership effectiveness and be equipped with latest leadership and management models and approaches for breakthrough steps in schools.

Given the dearth of research pertaining to a comprehensive model of school leadership effectiveness, the study incorporates valid leadership conceptualizations and influential determinants to contribute greater understanding to the existing body of literature on educational management and leadership. The model helps expand our knowledge by exemplifying the complexity surrounding the external and internal construction of leadership. Further, the model has direct implications for school administration and educational policy makers alike. The model is significant for school leaders who embrace and initiate changes by transitioning from a hierarchical (top-down) to a more collaborative, distributed, and ethical leadership practices. Profound knowledge and confidence in their perceived leadership abilities may encourage school leaders to be resilient when grappling with educational and social changes and may drive the continued pursuit of leadership roles. It is, therefore, recommended that the educational system offer school leaders further training on leadership and interpersonal skills which will optimize the effectiveness of their administrative and educational tasks.

The study unavoidably features several limitations. First, the main literature review methodology is addressed as a limitation, though this methodology allows a succinct review of commonly understood conceptualizations utilized to portray school leadership. Qualitative and/or quantitative data assessment would be complementarily and empirically verified and ascertained the developed model to gain more in-depth insights into these issues. Additionally, the proposed model is primarily reliant on three leadership styles, i.e. transformational, instructional, and moral leadership, and limited external and internal factors. As for the complexities of educational leadership, the authors concede that the framework with limited dimensions fails to present the richness in addressing influential determinants of school leadership effectiveness. Future research can, thus, tackle the hindrance by leveraging other widely cited leadership models and styles (i.e. transactional or participative leadership). Further, future studies may undertake cross-sectional or longitudinal research in a local or cross-cultural setting(s) for extrapolation and transferability of the findings in all levels of educational sector.

\section{REFERENCES}

Adair, J. (2010). Develop your leadership skills. Kogan Page.

Afshari, M., Bakar, K., Luan, W., Samah, B., \& Fooi, F. (2009). Technology and school leadership. Technology, Pedagogy and Education, 18(2), 235-248.

Avidov-Ungar, O., Friedman, I., \& Olshtain, E. (2014). Empowerment amongst teachers holding leadership positions. Teachers and Teaching, 20(6), 704-720.

Avolio, B., Walumbwa, F., \& Weber, T. (2009). Leadership: Current theories, research, and future directions. Annual Review of Psychology, 60, 421-449.

Baum, I., \& Baumann, N. (2019). Autonomous creativity: The implicit autonomy motive fosters creative production and innovative behavior at school. Gifted and Talented International, 33(1-2), 1-11.

Billig, M. (2014). Kurt Lewin's leadership studies and his legacy to social psychology: Is there nothing as practical as a good theory? Journal for the Theory of Social Behaviour, 45(4), 440-460.

Brown, M., \& Trevino, L. (2006). Ethical leadership: A review and future directions. The Leadership Quarterly, 17(6), 595-616.

Brown, M., Trevino, L., \& Harrisson, D. (2005). Ethical leadership: Social learning perspective for construct development and testing. Organizational Behavior and Human Decision Processes, 97(2), 117-130.

Bush, T. (2008). Leadership and management development in education. SAGE Publications Ltd.

Bush, T., \& Glover, D. (2003). School leadership: Concepts and evidence. Nottingham, England: National College for School Leadership.

Chen, Y., Cheng, J., \& Sato, M. (2017). Effects of school principals' leadership behaviors: A comparison between Taiwan and Japan. Educational Sciences: Theory \& Practice, 17, 145-173.

Christ, C., \& Dobbins, M. (2016). Increasing school autonomy in Western Europe: A comparative analysis of its causes and forms. European Societies, 18(4), 359-388.

Daft, R. (2008). The leadership experience (4th ed.) Thomson Higher Education.

Davis, S., Darling-Hammond, L., LaPointe, M., \& Meyerson, D. (2005). School leadership study: Developing successful principals (Review of Research). Stanford, CA: Stanford University, Stanford Educational Leadership Institute.

Day, C., \& Sammons, P. (2014). Successful school leadership. Education Development Trust. 
Denhardt, V., \& Campbell, B. (2005). Leadership education in public administration: finding the fit between purpose and approach. Journal of Public Affairs Education, 11(3), 169-179.

DeVita, M. (2005). Introduction: Getting the facts on school leadership preparation. In School leadership study: Developing successful principals; Davis, S., Darling-Hammond, L., LaPointe, M., Meyerson, D., Eds.; SELI/The Wallace Foundation.

Dufour, R., \& Marzano, R. (2011). Leaders of learning: How district, school, and classroom leaders improve student achievement. Bloomington: Solution Tree Press.

Engels, N., Hotton, G., Devos, G., Bouckenooghe, D., \& Aelterman, A. (2008). Principals in schools with a positive school culture. Educational Studies, 34(3), 159-174.

Fairman, J., \& Mackenzie, S. (2014). How teacher leaders influence others and understand their leadership. International Journal of Leadership in Education, 18(1), 61-87.

Felician, I. (2019). Interlinking public schools' organizational culture, principals' leadership styles and performance. Asian Journal of Research, 44-56.

Fidler, B. (1997). School leadership: Some key ideas. School Leadership and Management, 17 (1), 23-37.

Frederico, M., \& Whiteside, M. (2015). Building school, family, and community partnerships: Developing a theoretical framework. Australian Social Work, 69(1), 51-66.

Friedman, H. (2001). Moral leadership: Ancient lessons for modern times. Journal of College and Character, 2(11).

Greenfield, W. (2004). Moral leadership in schools. Journal of Educational Administration, 42(2), 174-196.

Gurley, D., Anast-May, L., O’Neal, M., \& Dozier, R. (2016). Principal instructional leadership behaviors: Teacher vs. selfperceptions. NCPEA International Journal of Educational Leadership Preparation, 11(1).

Gurr, D. (2015). A model of successful school leadership from the international successful school principalship project. Societies, 5, 136-150.

Hallinger, P. (2018). Bringing context out of the shadows of leadership. Educational Management Administration \& Leadership, 46(1), 5-24.

Hallinger, P., \& Bryant, D. (2013). Accelerating knowledge production on educational leadership and management in East Asia: A strategic analysis. School Leadership and Management, 33(3), 202-223.

Hallinger, P., \& Murphy, J. (1987). Assessing and developing principal instructional leadership. Educational Leadership, 45(1), 54-61.

Hallinger, P., \& Wang, W. (2015). Assessing instructional leadership with the principal instructional management rating scale. Springer International Publishing.

Hampden-Thompson, G., \& Galindo, C. (2016). School-family relationships, school satisfaction and the academic achievement of young people. Educational Review, 69(2), 248-265.

Hargreaves, D. (1995). School culture, school effectiveness and school improvement. School Effectiveness and School Improvement, 6(1), 23-46.

Hollenbeck, G., McCall, M., \& Silzer, R. (2006). Leadership competency models. The Leadership Quarterly, 17(4), 398413.

Hoy, A., \& Hoy, W. (2013). Instructional leadership: A research-based guide to learning in schools (4th ed). Pearson Education, Inc.

Hoy, W., \& Sweetland, S. (2007). Designing better schools: The meaning and nature of enabling school structures. In W. Hoy, \& M. DiPaola (Eds.), Essential ideas for the reform of American schools (pp. 339-366). Charlotte, NC: Information Age Publishing.

Hoy, W., \&Miskel, C. (2008). Educational administration: Theory, research, and practice (8th ed.). New York: McGrawHill.

Ibrahim, B., \& Don, Y. (2014). Servant leadership and effective changes management in schools. International Journal of Scientific and Research Publications, 4(1).

Inandi, Y., \& Giliç, F. (2016). Relationship of teachers' readiness for change with their participation in decision making and school culture. Educational Research and Reviews, 11(8), 823-833.

Judge, A., Bono, E., Llies, R., \& Gerhardt, W. (2002). Personality and leadership: A qualitative and quantitative review. Journal of Applied Psychology, 87(4),765-780.

Kalshoven, K., Den Hartog, D., \& De Hoogh, A. (2011). Ethical leadership at work questionnaire (ELW): Development and validation of a multidimensional measure. The Leadership Quarterly, 22(1), 51-69.

Karia, N., Hasmi, M., \& Asaari, A. (2019). Leadership attributes and their impact on work-related attitudes. International Journal of Productivity and Performance Management, 68(5), 903-919.

Keddie, A. (2014). School autonomy, accountability and collaboration: a critical review. Journal of Educational Administration and History, 47(1), 1-17.

Keddie, A., \& Holloway, J. (2019). School autonomy, school accountability and social justice: stories from two Australian school principals. School Leadership \& Management, 1-15.

Keddie, A., Gobby, B., \& Wilkins, C. (2017). School autonomy reform in Queensland: Governance, freedom and the entrepreneurial leader. School Leadership \& Management, 38(4), 378-394. 
Khan, Z., Bhat, J., \& Hussanie, I. (2017). Understanding leadership theories - A review for researchers. Asian Journal of Research in Social Sciences and Humanities, 7(5), 249-264.

Kotze, M., \& Venter, I. (2011). Differences in emotional intelligence between effective and ineffective leaders in the public sector: An empirical study. International Review of Administrative Sciences, 77(2), 397-427.

Langlois, L., Lapointe, C., Valois, P., \&De Leeuw, A. (2014). Development and validity of the ethical leadership questionnaire. Journal of Educational Administration, 52(3), 310-331.

Lee, A., Legood, A., Hughes, D., Tian, A., Newman, A., \& Knight, C. (2019). Leadership, creativity and innovation: A metaanalytic review. European Journal of Work and Organizational Psychology, 1-35.

Leithwood, K. (1994). Leadership for restructuring. Educational Administration Quarterly, 30, 498-518.

Lunenburg, F., \& Ornstein, A. (2012). Educational administration: Concepts and practices (6th ed.). Cengage Learning.

Mayger, L., \& Provinzano, K. (2020). Community school leadership: Identifying qualities necessary for developing and supporting equity-centered principals. Leadership and Policy in Schools, 1-22.

Miller, P. (2018). 'Culture', 'context', school leadership and entrepreneurialism: Evidence from sixteen countries. Education Science, 8(2), 1-12.

Mitchell, R. (2013). What is professional development, how does it occur in individuals, and how may it be used by educational leaders and managers for the purpose of school improvement? Professional Development in Education, 39(3), 387-400.

Mitchell, R., Sun, J., Zhang, S., Mendiola, B., \& Tarter, C. (2015). School effectiveness: A meta-analytic review of published research. In M. DiPaola, \& W. Hoy (Eds.), Leadership and school quality (pp. 161-169). Charlotte, NC: Information Age Publishing.

Molina, S. C. (2013). Family, school, community engagement, and partnerships: An area of continued inquiry and growth. Teaching Education, 24(2), 235-238.

Mulford, B. (2003). School leaders: Challenging roles and impact on teacher and school effectiveness. The Organisation for Economic Co-operation and Development (OECD) Commissioned Paper.

Norris, S. (2008). An examination of self-leadership. Emerging Leadership Journeys, 1(2), 43-61.

Northouse, P. (2016). Leadership: Theory and practice (7th ed.). Thousand Oaks, CA: Sage Publications.

Parveen, K., Phuc, T. Q. B., Shafiq, M., \& Wei, T. (2021). Identifying the administrative challenges encountered by the principals in low-performing public secondary schools of Faisalabad District, Pakistan. International Journal of Humanities and Innovation (IJHI), 4(1), 5-16.

Pont, B., Nusche, D., \& Moorman, H. (2008). Improving school leadership-Volume 1: Policy and practice. OECD Publishing.

Quick, P., \& Normore, A. (2004). Moral leadership in the 21st century: Everyone is watching-especially the students. The Educational Forum, 68(4), 336-347.

Reitzug, U., West, D., \& Angel, R. (2008). Conceptualizing instructional leadership-The voices of principals. Education and Urban Society, 40(6), 694-714.

Retna, K. (2015). Different approaches to the professional development of principals: A comparative study of New Zealand and Singapore. School Leadership \& Management, 35(5), 524-543.

Schleicher, A. (2012). Preparing teachers and developing school leaders for the 21st century: Lessons from around the world (Ed.). OECD Publishing.

Schleicher, A. (2015). Schools for 21st-century learners: Strong leaders, confident teachers, innovative.International Summit on the teaching profession. OECD Publishing.

Schratz, M., \& Schley, W. (2014). Educational leaders as change agents in system development: The Austrian Leadership Academy. Journal of Contemporary Educational Studies, 4, 12-29.

Seemiller, C., \& Croft, L. (2017). Developing leadership competencies. New Directions for Student Leadership, 156, 717.

Sincar, M. (2013). Challenges school principals facing in the context of technology leadership. Educational Sciences: Theory \& Practice, 3(2), 1273-1284.

Skaalvik, E., \& Skaalvik, S. (2014). Teacher self-efficacy and perceived autonomy: Relations with teacher engagement, job satisfaction, and emotional exhaustion. Psychological Reports: Employment Psychology \& Marketing, $114(1), 68-77$

Solinger, O., Jansen, P., \& Cornelissen, J. (2019). The emergence of moral leadership. Academy of Management Review, 45(3), 1-60.

Solomon, A., \& Steyn, R. (2017). Leadership style and leadership effectiveness: Does cultural intelligence moderate the relationship? Acta Commercii - Independent Research Journal in the Management Sciences, 17(1), 1-13.

Stevenson, M., Hedberg, J., O’Sullivan, K., \& Howe, C. (2016). Leading learning: The role of school leaders in supporting continuous professional development. Professional Development in Education, 42(5), 818-835.

Tam, V., Chan, J., Li, S., \& Pow, J. (2017). Developing and managing school human capital for information and communication technology integration: A case study of a school-based e-learning project in Hong Kong. International Journal of Leadership in Education, 21(4), 447-461.

The Center for Leadership Studies. (2017). Situational leadership relevant then relevant now. 
The Wallace Foundation (2009). Assessing the effectiveness of school leaders: New directions and new processes. www.wallacefoundation.org.

Thompson, G., \& Glasø, L. (2015). Situational leadership theory: A test from three perspectives. Leadership \& Organization Development Journal, 36(5), 527-544.

Tomlinson, H. (2004). Educational leadership personal growth for professional development. SAGE Publications Ltd.

Turan, S., \& Bektas, F. (2013). The relationship between school culture and leadership practices. Egitim ArastirmalariEurasian Journal of Educational Research, 52, 155-168

Uğur, N., \& Koç., T. (2019). Leading and teaching with technology: School principals' perspective. International Journal of Educational Leadership and Management, 7(1), 42-71.

Valli, L., Stefanski, A., \& Jacobson, R. (2016). School-community partnership models: Implications for leadership. International Journal of Leadership in Education, 21(1), 31-49.

Vroom, V., \& Jago, A. (2007). The role of situation in leadership. American Psychologist, 62, 17-24.

Wadesango, N. (2012). The influence of teacher participation in decision-making on their occupational morale. Journal of Social Sciences, 31(3), 361-369.

Waldron, N., \& McLeskey, J. (2010). Establishing a collaborative school culture through comprehensive school reform. Journal of Educational and Psychological Consultation, 20(1), 58-74.

Wales, J., Magee, A., \& Nicolai, S. (2016). How does political context shape education reforms and their success? Lessons from the Development Progress project. Overseas Development Institute.

Welch, J., \& Hodge, M. (2017). Assessing impact: The role of leadership competency models in developing effective school leaders. School Leadership \& Management, 38(4), 355-377.

Zachariou, A., Kadji-Beltran, C., \& Manoli, C. (2013). School principals' professional development in the framework of sustainable schools in Cyprus: A matter of refocusing. Professional Development in Education, 39(5), $712-731$.

Publisher's note: Science Impact Publishers remain neutral with regard to jurisdictional claims in published maps and institutional affiliations.

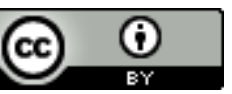

Open Access This article is licensed under a Creative Commons Attribution 4.0 International License, which permits use, sharing, adaptation, distribution and reproduction in any medium or format, as long as you give appropriate credit to the original author(s) and the source, provide a link to the Creative Commons license and indicate if changes were made. The images or other third-party material in this article are included in the article's Creative Commons license, unless indicated otherwise in a credit line to the material. If material is not included in the article's Creative Commons license and your intended use is not permitted by statutory regulation or exceeds the permitted use, you will need to obtain permission directly from the copyright holder. To view a copy of this license, visit https://creativecommons.org/licenses/by/4.0/.

(C) The Author(s) 2020 